\title{
Balloon Aortic Valvuloplasty: Results of the Valvuloplasty and Angioplasty of Congenital Anomalies Registry
}

\author{
Albert P. Rocchini, MD, Robert H. Beekman, MD, Giora Ben Shachar, MD, Lee Benson, MD, \\ David Schwartz, MD, and Jean S. Kan, MD
}

\begin{abstract}
Data from 204 children and infants who underwent aortic balloon valvuloplasty between 1982 and 1986, reported to the Valvuloplasty and Angioplasty of Congenital Anomalies Registry, were reviewed. Valvuloplasty was successful in 192 of 204 children, reducing the peak systolic left ventricular ejection gradient from $77 \pm 2$ to $30 \pm 1 \mathrm{~mm} \mathrm{Hg}$, p $<0.001$. The same degree of aortic stenosis gradients reduction was noted in both the 38 children under 1 year of age and in the 166 children over 1 year of age. Significant complications included death, aortic regurgitation and femoral artery thrombosis or damage. The incidence of these complications correlated with the age of the child, the ratio of valvuloplasty balloon size/anulus size, or both. The data suggest that percutaneous balloon valvuloplasty provides effective acute relief of valvar aortic stenosis in both infants and children. However, long-term follow-up data are necessary before balloon valvuloplasty can be established as a treatment of choice for congenital valvar aortic stenosis.
\end{abstract}

(Am J Cardiol 1990;65:784-789)

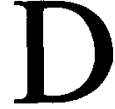
uring the past 5 years percutaneous balloon valvuloplasty has become the treatment of choice for valvar pulmonary stenosis. ${ }^{1-6}$ Balloon angioplasty, however, still remains an experimental procedure for unoperated left-sided obstructive lesions. ${ }^{7,8}$ Lababidi et $a^{8,9}$ recently reported that percutaneous balloon dilation could be used to successfully treat valvar aortic stenosis. Others have also reported that valvuloplasty can successfully treat valvar aortic stenosis in both children ${ }^{10-15}$ and adults. ${ }^{16-19}$ However, the total reported experience with balloon angioplasty to treat valvar aortic stenosis in the pediatric population is thus far only 58 patients. In an attempt to evaluate the efficacy and safety of balloon valvuloplasty to treat children with valvar aortic stenosis in a large population, the results of Valvuloplasty and Angioplasty of Congenital Anomalies (VACA) Registry were reviewed.

\section{METHODS}

Patient population: Balloon aortic valvuloplasty was performed in 204 children (10.1 \pm 0.84 years of age) and the results were reported to the VACA Registry from January 1982 through December 1986. The age distribution of the patients is shown in Figure 1. All members of the VACA Registry were asked to complete a questionnaire on all patients in whom they performed balloon aortic valvuloplasty. The questionnaire contained the following information: date of birth, date of procedure, left ventricular and aortic pressures and cardiac output indexes beforc and immediatcly after valvuloplasty, aortic anulus dimension, valvuloplasty balloon dimension, inflation pressure and any complications associated with the procedure. The data from the VACA Registry were then analyzed and form the basis of this report.

No attempt was made by the registry to standardize valvuloplasty indications, the methods used to perform valvuloplasty or to obtain any follow-up information after valvuloplasty. A single valvuloplasty balloon (ranging in diameter from 4 to $25 \mathrm{~mm}$ ) was used in $163 \mathrm{sub}$ jects and 2 balloons side by side (ranging in diameter from 5 to $18 \mathrm{~mm}$ ) were used in 23 subjects. Neither the balloon size nor number used were specified in 18 subjects.

Statistical analysis: The data are presented as mean \pm standard deviation. Comparisons were made using either a 2-tailed $t$ test for paired observations, analysis of variance or chi-square testing. Linear regression analysis was used to determine if a relation existed between 
the ratio of balloon size/anulus size or patient age and the decrease in left ventricular pressure or outflow tract gradient. A p value $<0.05$ was required as evidence of significance.

\section{RESULTS}

Hemodynamic data: Table I lists hemodynamic data before and immediately after valvuloplasty from all 204 subjects who had aortic balloon valvuloplasty attempted. The peak systolic ejection gradient significantly decreased from $77 \pm 28$ to $30 \pm 14 \mathrm{~mm} \mathrm{Hg}$ ( $p<0.001)$ (Figure 2). The decrease in peak systolic ejection gradient was due to the combination of a significant decrease in left ventricular systolic pressure $(p<0.001)$ and a significant increase in aortic systolic pressure ( $p$ $<0.001$ ) (Table I). No significant changes in cardiac index, aortic diastolic pressure or left ventricular enddiastolic pressure were observed after valvuloplasty. No relation was observed between the change in left ventricular systolic pressure or the change in left ventricular outflow tract gradient and age for the group considered as a whole (age vs change in gradient $r=1.23$; age vs change in left ventricular pressure $r=-0.08$ ), or for infants ( $<1$ year of age) versus older children (Figure 3 ). However, the results were poorer in those neonates in whom angioplasty was performed in the first week of life compared to the group as a whole $(p<0.001)$ or compared to infants between the ages of 8 days and 1 year $(p<0.001)$. In addition, neither the valvuloplasty balloon size, the ratio of balloon/anulus diameters nor the use of 1 or 2 valvuloplasty balloons correlated with the degree of reduction in left ventricular systolic pressure or outflow tract gradient.

Operative aortic valvotomy was subsequently required in $4 \%$ ( 8 of 204) of the children. Balloon valvuloplasty could not be performed in 4 of these patients because it was not possible to cross the aortic valve in a retrograde fashion. Serious complications occurred before performing the valvuloplasty in 2 children (left ventricular perforation and valvuloplasty catheter malfunc-
TABLE I Hemodynamic Data Before and After Valvuloplasty in 186 Children for Whom Complete Data Were Reported to the Registry

\begin{tabular}{|c|c|c|c|c|}
\hline & No. & $\begin{array}{l}\text { Before } \\
\text { Valvuloplasty }\end{array}$ & $\begin{array}{l}\text { After } \\
\text { Valvuloplasty }\end{array}$ & $p$ Value \\
\hline $\begin{array}{l}\text { LV systolic } \\
\text { pressure } \\
(\mathrm{mm} \mathrm{Hg})\end{array}$ & 186 & $174 \pm 40$ & $133 \pm 27$ & $<0.001$ \\
\hline $\begin{array}{l}\text { LVED pressure } \\
(\mathrm{mm} / \mathrm{lg})\end{array}$ & 157 & $13 \pm 5$ & $12 \pm 6$ & 0.19 \\
\hline $\begin{array}{c}\text { AO systolic } \\
\text { pressure } \\
(\pi \mathrm{rr} / \mathrm{Hg})\end{array}$ & 186 & $96 \pm 13$ & $104 \pm 13$ & $<0.001$ \\
\hline $\begin{array}{c}\text { AO diastolic } \\
\text { pressure } \\
\text { (mm Hg) }\end{array}$ & 186 & $63 \pm 13$ & $65 \pm 13$ & 0.11 \\
\hline $\begin{array}{l}\text { Cardiac index } \\
\quad\left(\text { liters } / \mathrm{min} / \mathrm{m}^{2}\right)\end{array}$ & 103 & $4.1 \pm 1$ & $3.9 \pm 1$ & 0.06 \\
\hline
\end{tabular}

tion, nos. 9 and 10, Table II). The valvuloplasty was performed but did not effectively reduce the left ventricular outflow tract gradient to a nonsurgical level in the remaining 2 subjects. The left ventricular outflow gradient only decreased from 80 to $60 \mathrm{~mm} \mathrm{Hg}$ in 1 child and in the other, an infant, acidosis and seizures persisted despite a modest reduction in gradient $(70$ to $40 \mathrm{~mm}$ $\mathrm{Hg}$ ) (no. 5, Table II)

Complications: Major life-threatening complications occurred in 11 of 204 subjects (5\%) (Table II). Five of the 11 children, all $<1$ year of age, died either during the procedure ( 4 of 5 ) or within 2 days of the valvuloplasty procedure ( 1 of 5$)$. There were several specific causes of death in each of these 5 . A 7-mm balloon catheter could not be advanced from the right femoral artery into the abdominal aorta in the first infant. On withdrawal of the catheter the iliac/femoral artery was torn and the child exanguinated. Valvuloplasty was not performed. A second infant had undergone a surgical valvotomy at 6 days of age. Due to persistent congestive
FIQURE 1. The age distribution of the 204 children who underwent balloon aortic valvuloplasty.

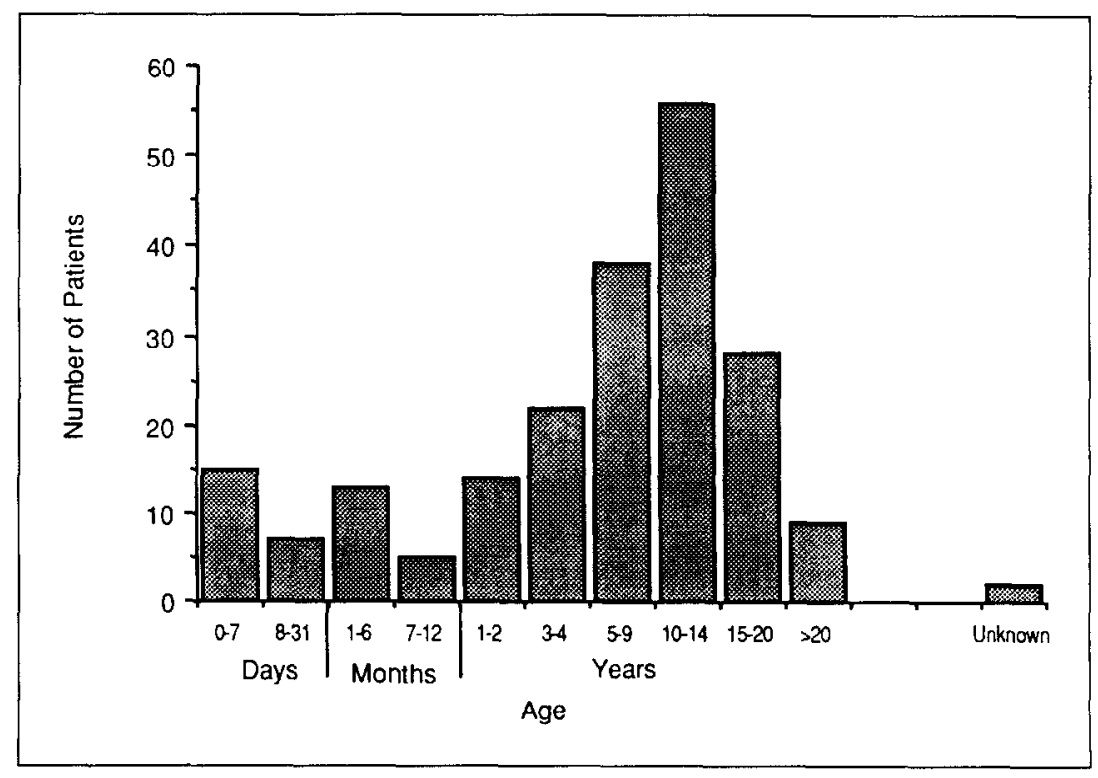


failure, aortic valvuloplasty was attempted. After the valvuloplasty the infant developed hypotension and bradycardia, and an aortogram demonstrated severe aortic regurgitation. The patient died approximately 1 hour after the valvuloplasty. Necropsy examination revealed complete avulsion of the posterior aortic cusp. A third infant experienced a cardiac arrest and died due to aortic valve perforation and severe aortic insufficiency. A fourth infant had a combination of severe valvar aortic stenosis and a mild supravalvar stenosis. The infant died from tamponade shortly after the procedure. The ascending aorta was found to be very hypoplastic and a tear in the aortic root at the supravalvar ridge was noted at autopsy. The fifth infant (previously mentioned) died 2 days after an unsuccessful balloon valvuloplasty and subsequent surgical valvotomy. At necropsy, the infant was noted to have a transverse, circumferential tear in the aorta at the origin of the left common carotid artery.

Other major complications included life-threatening arrhythmias in 3 patients, and in 1 child each perforation of the left ventricle, requiring emergency pericardiocentesis and surgery; dislodgement of the balloon portion of the valvuloplasty catheter in the ascending aorta over a guidewire in the left ventricle requiring emergency surgery to remove the balloon; and perforation of the mitral valve (while performing balloon aortic valvuloplasty using an anterograde approach across the atrial septum) requiring surgical repair of the mitral valve. Major complications were significantly related to age at valvuloplasty. Nine of 38 children $<1$ year of age developed a major complication whereas only 2 of 166 over 1 year of age had complications, yielding a relative

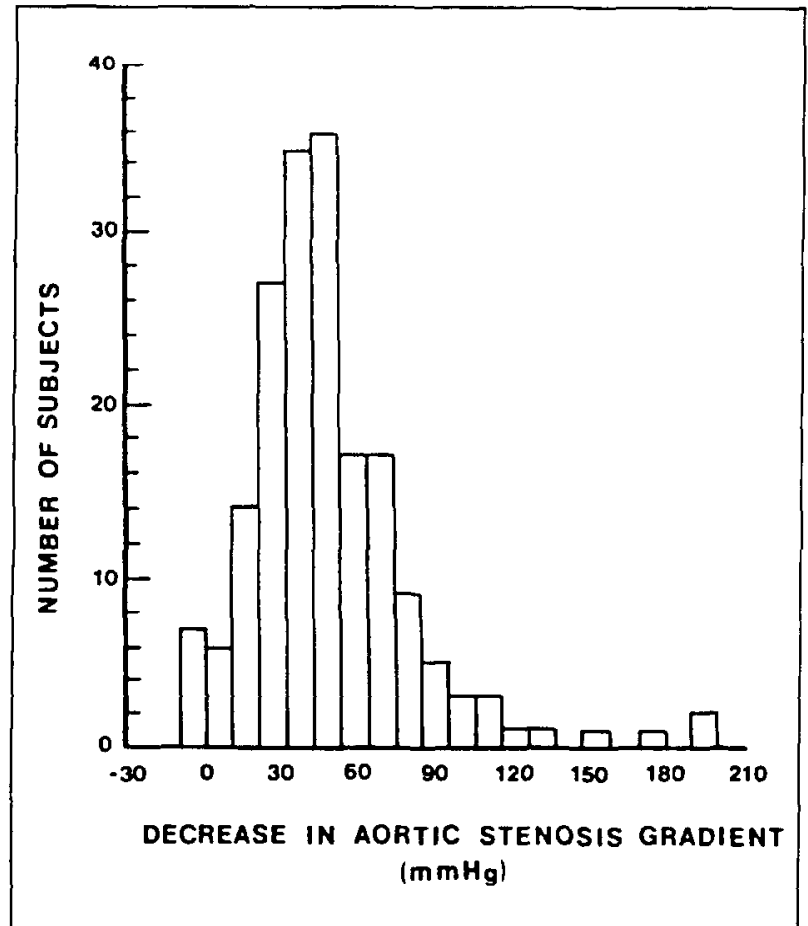

FGURE 2. The distribution of change in aortic stenosis gradient for the $\mathbf{2 0 4}$ children who underwent balloon aortic valuuloplasty. risk of 25.5 for major complications in infancy (chisquare $=28.2 ; \mathrm{p}<0.001$ ). Angioplasty performed during the first month of life is associated with the highest rate of complications (Figure 4).

Aortic regurgitation developed or increased in severity in 21 of 204 children. The aortic regurgitation increased by $\leq 1$ degree in 14 of the children, while the increase in regurgitation was moderate in 3 children and severe in 4 . No difference in the incidence of aortic insufficiency existed between those patients under the age of 1 year ( 6 of 38) and those over the age of 1 year at the time of valvuloplasty (15 of 160). A significant relation was noted between the development of and severity of aortic insufficiency and the ratio of valvuloplasty balloon size/aortic anulus size (Figure 5).

Finally, significant bleeding requiring transfusion $0 c-$ curred in 5 of 204, while arterial thrombosis or damage was associated with the valvuloplasty procedure in 25 of $204(12 \%)$. Permanent loss of the femoral artery pulse occurred in 5 of $25(20 \%)$ children. Three resulted from femoral arteries that could not be repaired. No explanation for the failure of femoral pulse to return to normal was given in 2 others. In the other 20 of 25 children the femoral pulse returned to normal after treatment with heparin in 4 , streptokinase or urokinase in 7 , or after surgical thrombectomy in 6 . A significant association between age and femoral thrombosis was observed. Loss of femoral pulse occurred in 12 of 38 children under the age of 1 while only 13 of 160 children over the age of 1 lost the femoral pulse (relative risk $=5.2$, chi-square $=$ $86, p=0.005$ ). In an attempt to evaluate the relation between valvuloplasty balloon size (independent of age) and the incidence of femoral artery thrombosis, we compared the ratio of balloon size/anulus between those children who did and did not develop arterial thrombosis. The ratio of balloon size/anulus size was significantly larger in those children who developed arterial thrombosis $(0.99 \pm 0.7$ vs $0.91 \pm 0.03, \mathrm{p}=$ 0.023).

\section{Discussion}

Hemodynamic results: The management of infants and children with moderate to severe aortic stenosis can be challenging. When indicated, surgical aortic valvotomy is an effective means of reducing the aortic stenosis gradient with a low mortality of 1 to $2 \%$ in children over the age of 1 year. ${ }^{20-24}$ Surgical valvotomy must be considered palliative therapy, however, since aortic regurgitation may occur and restenosis is common. ${ }^{25-29}$ The present study suggests that percutaneous balloon valvuloplasty may provide an effective alternative to surgical palliation of valvar aortic stenosis in infants and children ( $>1$ week of age). Balloon valvuloplasty of the aortic valve decreased the peak systolic ejection gradient across the aortic valve in 192 of 204 infants and children to levels comparable to those achieved by surgical valvotomy. For children $>1$ year of age aortic stenosis gradients after valvuloplasty averaged $30 \pm 6 \mathrm{~mm} \mathrm{Hg}$ and for children $<1$ year of age the gradients averaged $27 \pm 51 \mathrm{~mm} \mathrm{Hg}$ (Figure 3). Jones et al ${ }^{21}$ recently reported the results of surgical aortic valvotomy in 41 
children with valvar aortic stenosis over 1 year of age. Cardiac catheterization performed 1 year postoperatively showed a mean residual aortic gradient of $28 \mathrm{~mm}$ $\mathrm{Hg}$. These other reports indicate that surgical valvotomy can be expected to reduce the left ventricular outflow tract gradient to approximately 25 to $40 \mathrm{~mm} \mathrm{Hg}$, results comparable to those observed in this study. ${ }^{21-29}$

The mechanism by which balloon valvuloplasty reduces the gradient in congenital valvar aortic stenosis has not been clearly defined, but evidence suggests that tears are produced along lines of commissural fusion. McKay et al $^{30}$ performed necropsy or intraoperative balloon dilation in 3 patients with aortic stenosis and commissural fusion ( 1 with congenital bicuspid and 2 with postrheumatic aortic stenosis). In each instance, balloon dilation resulted in separation of the fused commissures along the commissural lines. Lababidi et al ${ }^{8,9}$ reported intraoperative observations of the aortic valve in 2 children who underwent elective surgical valvotomy after unsuccessful percutaneous balloon valvuloplasty. Each bicuspid aortic valve was found to have a 2- to 4$\mathrm{mm}$ tear along the free edge of the fused commissure. The anatomic changes after more successful balloon aortic valvuloplasty in childhood have not been reported.

Complications: In addition to documenting the acute efficacy of balloon aortic valvuloplasty for the treatment of valvar aortic stenosis, this study also documents a number of complications directly associated with the procedure, including death, aortic regurgitation, femoral artery thrombosis or damage, excessive blood loss, life-threatening arrhythmias and damage to other cardiac structures. Four deaths were directly related to the valvuloplasty procedure, and all 4 occurred in infants under the age of 3 months. However, critical aortic stenosis carries a grave prognosis even if treated surgically. ${ }^{31-36}$ In a recent report by Pelech et al, ${ }^{31}$ survival for neonates undergoing surgical therapy for critical aortic stenosis was only $43 \%$. Even though the registry data do not specify why the 38 infants underwent balloon aortic valvuloplasty as opposed to surgical therapy, the survival rate of $87 \%$ for the valvuloplasty group is remarkable. When the causes of death in these infants were reviewed, we found that 1 of these deaths (no. 1,
TABLE II Major Life-Threatening Complications Associated with Aortic Balloon Valvuloplasty

\begin{tabular}{|c|c|c|c|c|}
\hline Pt No. & Age & $\begin{array}{l}\text { Balloon } \\
(\mathrm{mm})\end{array}$ & $\begin{array}{l}\text { Anulus } \\
(\mathrm{mm})\end{array}$ & Complication \\
\hline 1 & $\leq 1 \mathrm{mo}$ & 7 & 7 & $\begin{array}{l}\text { Death due to esanguina- } \\
\text { tion from a torn iliac/ } \\
\text { femoral artery }\end{array}$ \\
\hline 2 & $\leq 1 \mathrm{mo}$ & 6 & 6 & $\begin{array}{l}\text { Death due to avulsion of } \\
\text { posterior cusp of aortic } \\
\text { valve }\end{array}$ \\
\hline 3 & $\leq 1 \mathrm{mo}$ & 5 & 5.5 & $\begin{array}{l}\text { Death due to aortic valve } \\
\text { perforation }\end{array}$ \\
\hline 4 & $3 \mathrm{mos}$ & 6 & 9 & $\begin{array}{l}\text { Death due to rupture of } \\
\text { ascending aorta at the } \\
\text { site of a supravalvar } \\
\text { ridge }\end{array}$ \\
\hline 5 & $\leq \mathrm{Imo}$ & 5 & 6 & $\begin{array}{l}\text { Death due to unsuccess- } \\
\text { ful valvuloplasty and } \\
\text { surgery; tear in aorta } \\
\text { at autopsy }\end{array}$ \\
\hline 6 & $\leq 1 \mathrm{mo}$ & 5 & - & $\begin{array}{l}\text { Bradycardia requiring re- } \\
\text { suscitation }\end{array}$ \\
\hline 7 & $\leq 1 \mathrm{mo}$ & 5 & - & $\begin{array}{l}\text { Bradycardia requiring dis- } \\
\text { continuing procedure }\end{array}$ \\
\hline 8 & $\leq 1 \mathrm{mo}$ & 6 & 10 & $\begin{array}{l}\text { Ventricular fib. during } \\
\text { catheter exchange }\end{array}$ \\
\hline 9 & $\leq 1 \mathrm{mo}$ & - & 6 & $\begin{array}{l}\text { LV perforation requiring } \\
\text { emergency open heart } \\
\text { surgery }\end{array}$ \\
\hline 10 & $14.9 \mathrm{yrs}$ & 25 & 31 & $\begin{array}{l}\text { Catheter malfunction re- } \\
\text { quiring open heart sur- } \\
\text { gery }\end{array}$ \\
\hline 11 & $9.6 \mathrm{yrs}$ & 20 & 24 & $\begin{array}{c}\text { Mitral valve tear requiring } \\
\text { open heart surgery }\end{array}$ \\
\hline
\end{tabular}

Table II) may have been prevented if balloons on smaller catheter shafts had been available.

Aortic regurgitation occurred in $10 \%$ of the children, a figure less than that reported by others. ${ }^{8}{ }^{80.11}$ Mild to moderate aortic regurgitation has been reported in 10 to $28 \%$ of patients after surgical valvotomy. ${ }^{26,27}$ Although the mechanism by which balloon valvuloplasty produces aortic regurgitation has not been clearly defined, perforation of an aortic valve leaflet and avulsion of cusp tissue from the anulus were observed in 2 of the infants who died (nos. 2 and 3, Table II). We observed a relation between the ratio of balloon/anulus size and both

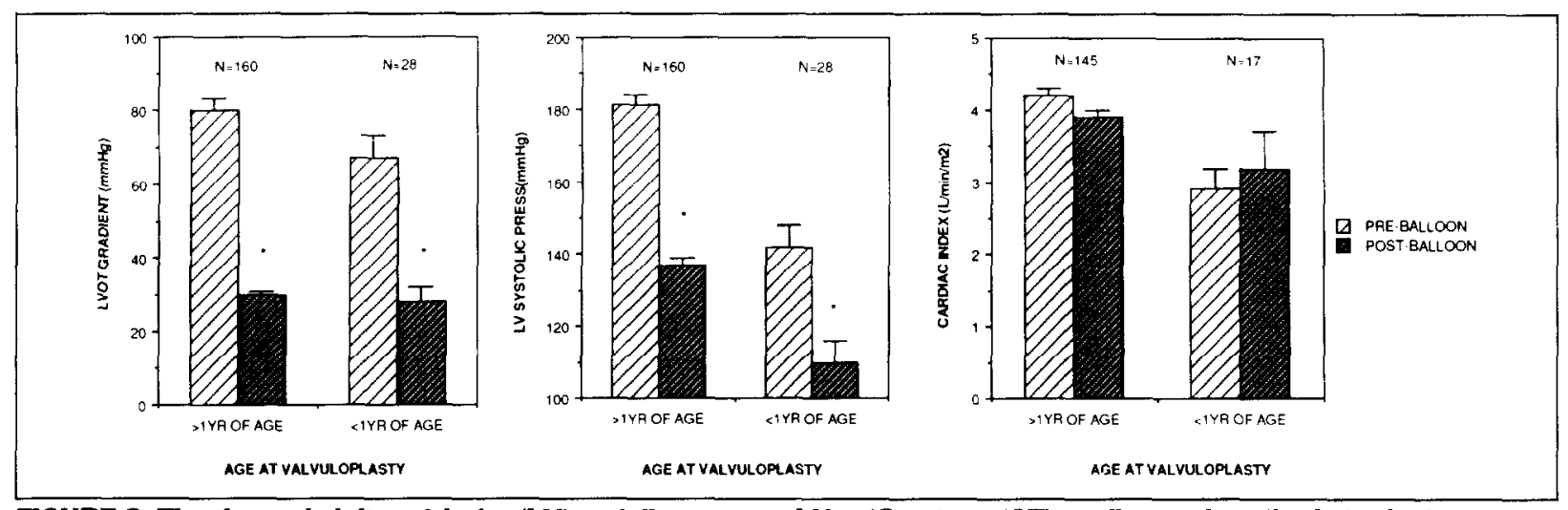

FIGURE 3. The change in left ventricular (LV) systolic pressure, LV outflow tract (OT) gradient and cardiac index in those children less than and greater than 1 year of age at the time of aortic valviloplasty. All values are mean \pm standard error of the mean. * $p<0.001$, before and after valvuloplasty. 


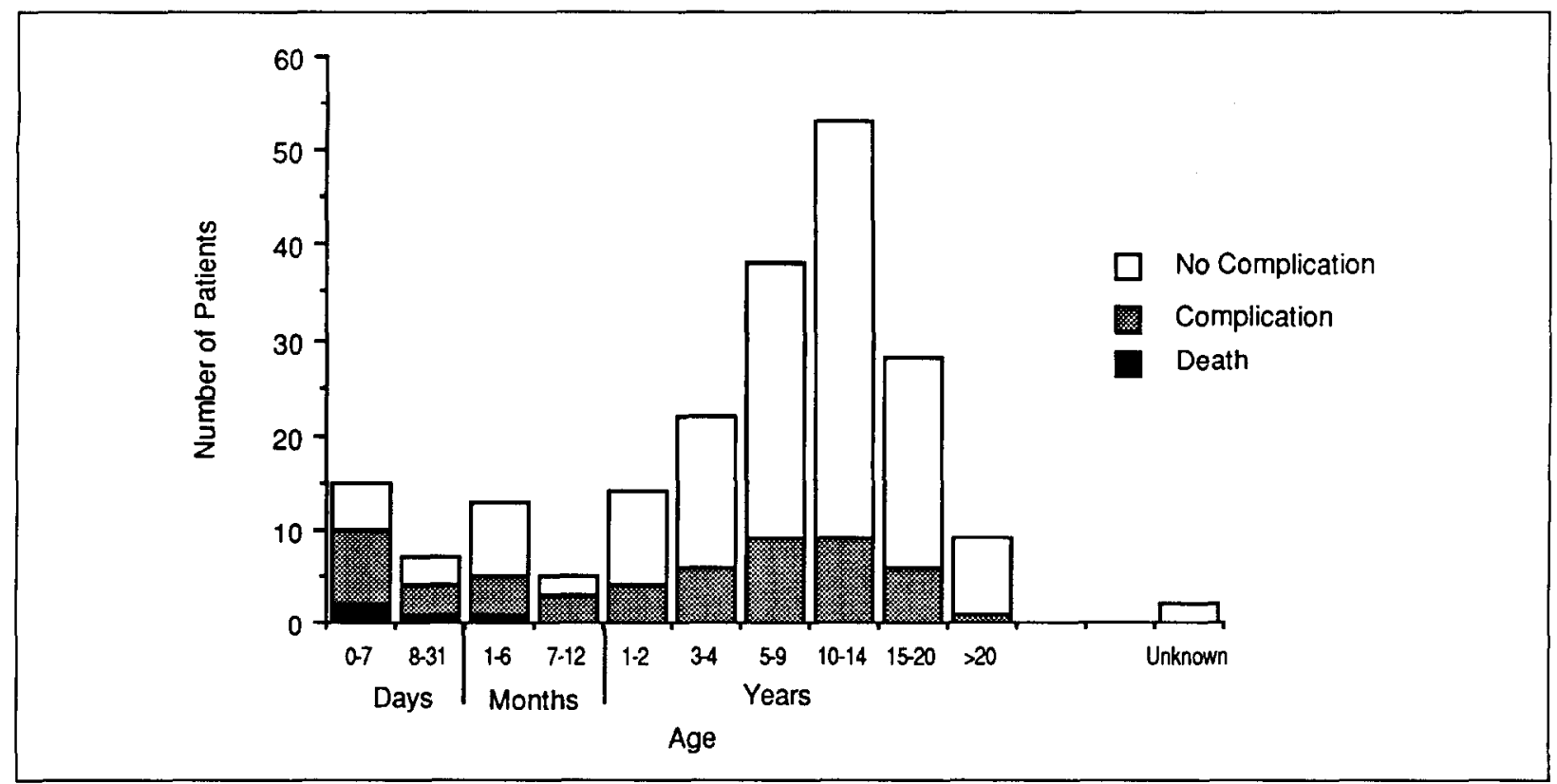

FIGURE 4. The distribution of belloon aortic valudoplasty compllcation rate by age. The highest incidence of complications occurred in children $<1$ month of age.

the presence and severity of aortic regurgitation; the incidence of aortic regurgitation might be reduced by using smaller balloons.

Femoral artery thrombosis, damage or both occurred in $12 \%$ of the children, and was most common in children under 1 year of age. Femoral artery patency was restored either with medical (heparin, streptokinase or urokinase) or surgical therapy in the majority of in-

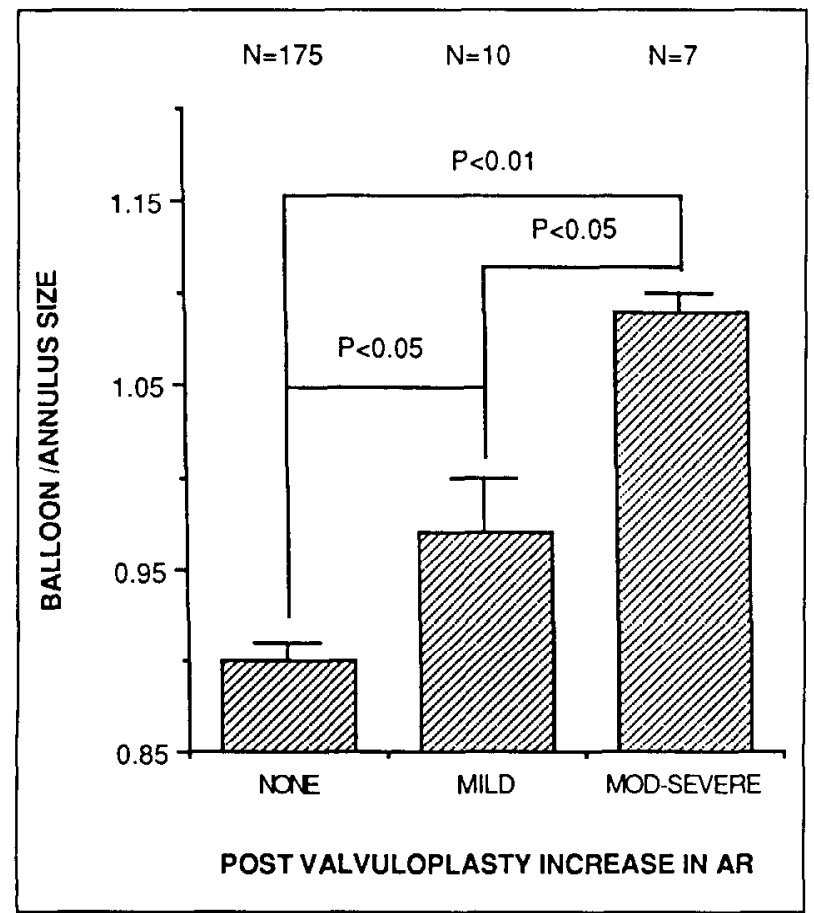

FIGURE 5. The relation between the ratio of valvuloplasty balloon size to aortic anulus size and development of aortic regurgitation (AR) after balloon valvuloplasty. All values are mean \pm standard error of the mean. MOD-SEVERE = moderate to severe. stances ( $80 \%$ of the time). Since the development of femoral artery damage was significantly related to both patient age and balloon/anulus ratio, the incidence of this complication may be significantly reduced by the development of new catheters with a smaller shaft size and a lower balloon profile.

Study limitations: Two major limitations exist. First, since the VACA Registry only collected data on the acute response to aortic balloon valvuloplasty, we have no information to document the long-term efficacy of this procedure. However, based on the reported experience of others, ${ }^{8-11,14}$ all of whose patients are included in this report, one can postulate that gradient reduction is likely for at least 1 year. To document the true longterm efficacy of aortic balloon valvuloplasty a multicenter long-term follow-up study, including repeat catheterization, will be necessary.

The second limitation is that no attempt was made by the registry to standardize the methods used to perform the valvuloplasty; thus, only limited conclusions can be made concerning the technical aspects of the valvuloplasty procedure. In children in whom a single valvuloplasty balloon was used (balloon/anulus ratio of 0.56 to 1.5 ), no relation was noted between balloon/ anulus ratio and aortic stenosis gradient reduction. Since the complications of aortic regurgitation and femoral artery injury appear to relate to balloon/anulus ratio and since Helgason et $\mathrm{al}^{11}$ have shown that a balloon/anulus ratio of $>1.2$ produced damage to aortic valve leaflets, mitral valve leaflets and intraventricular septum in normal lambs, a balloon/anulus ratio of $\leq 1$ should be used.

Clinical implications: These data suggest that percutaneous balloon valvuloplasty provides effective acute relief of valvar aortic stenosis in both infants $(>1$ week of age) and children. Significant complications of the valvuloplasty procedure included death, aortic regurgi- 
tation and femoral artery thrombosis or damage. These complications, however, appeared to be uncommon if valvuloplasty was performed on children older than 1 month of age, and if the balloon/anulus size ratio was $\leq 1.0$. Long-term follow-up data should be collected before percutaneous balloon valvuloplasty can be established as treatment of choice for children with valvar aortic stenosis.

Acknowledgment: We would like to thank Gerald Serwer, MD, for assistance in the analysis of the data.

\section{REFERENCES}

1. Kveselis DA, Rocchini AP. Percutaneous transluminal angioplasty of peripheral pulmonary artery stenosis, coarctation of the aorta, superior vena caval and pulmonary venous stenosis and other great artery stenoses. Semin Intervent $R a$ diol 1984:1:201-215.

2. Lock JE, Keane JF, Fellows KE. The use of catheter interventional procedures for congenital heart disease. JACC 1967,7:1420-1423.

3. Rocchini AP, Kveselis DA, Crowley D, Dick M, Rosenthal A. Percutaneous balloon valvuloplasty for treatment of congenital pulmonary valvular stenosis in children. Am J Cardiol 1984;3:1005-1012.

4. Kan JS, White RI, Mitchell SE, Gardner TJ, Percutaneous balloon valvuloplasty: a new method for treating congenital pulmonary-valve stenosis. $N$ Engl $J$ Med 1982:307:540-542.

5. Kan JS, White RI, Mitchell SE, Anderson JH, Gardner TJ. Percutaneous transluminal balloon valvuloplasty for pulmonic valve stenosis. Circulation $1984,69: 554-560$

6. Kveselis DA, Rocchini AP, Snider AR, Rosenthal A, Crowley DC, Dick M. Results of halloon valvuloplasty in the treatment of congenital valvar pulmonary stenosis in children. Am $J$ Cardiol 1985:56:527-532.

7. Lock JE, Bass JL, Amplatz K. Fuhrman BP, Castaneda-Zuniga WR. Balloon dilatation angioplasty of coarctations in infants and children. Circulation 1983;68:109-116

8. Lababidi $\mathrm{Z}, \mathrm{Wu} J \mathrm{R}$, Walls TJ. Percutaneous balloon aortic valvuloplasty: results in 23 patients. Am J Cardiol 1984;53:194-197.

9. Walts J I, Lababidi $\angle$, Curtes JJ, Silver D. Assessment of percutaneous balloon pulmonary and aortic valvuloplasty. $J$ Thorac Cardiovasc Surg 1984;88:352-356. 10. Choy M, Beckman RH, Rocchini AP, Crowley DC, Snider AR, Dick M, Rosenthal A. Percutaneous balloon valvuloplasty for aortic stenosis in infants and children. Am J Cardiol 1987;59:1010-1013.

11. Helgason H, Keane JF, Fellows KE, Kulik TJ, Lock JE. Balloon dilation of the aortic valve. Studies in normal lambs and in children with aortic stenosis. JACC 1987;9:816-822.

12. Sanchez GR, Mehta AV, Ewing LL, Brickley SE, Anderson TM, Black IFA. Successful percutaneous balloon valvuloplasty of the aortic valve in an infant. Pediatr Cardiol 1985,6:103-106.

13. Rupprath G, Neuhaus KL. Percutaneous balloon aortic valvuloplasty in infancy and childhood. Am $J$ Cardiol 1985:55:1855-1856.

14. Waller BF, Girod DA, Dillion JC. Transverse aortic wall tears in infants after balloon angioplasty for aortic valve stenosis: relation of aortic wall damage to diameter of inflated angioplasty balloon and aortic lumen in seven necropsy cases. JACC 1984,4:1235-1241.
15. Richards At, Somerville J. Successful balloon aortic valvotomy in a child with a pulmonary hypertensive duct and aortic valve stenosis. Br Heart $J$ 1986:56:185-186

16. McKay RG, Saflan RD, Lock JE, Diver DJ, Berman AD, Warren SE, Come PC, Baim DS, Mandell VE, Royal HD, Grossman W. Assessment of left ventricular and aortic valve function after aortic balloon valvuloplasty in adult patients with critical aortic stenosis. Circulation 1987,75:192-203.

17. Cribier A, Souudi N, Berland J, Savin T, Rocha P, Letac B. Percutaneous transluminal valvuloplasty of acquired aortic stenosis in elderly patients: an alternative to valve replacement? Lancet 1986:1:63-67.

18. Isner JM, Salem DN, Desnoyers MR, Hougen TH, Mackey WC, Pandian NG, Eickhorn EJ, Konstam MA, Levine HJ. Treatment of calcific aortic stenosis by balloon valvuloplasty. Am J Cardiol 1987;59:313-3I7.

19. Sifian RD, Mandeil VS, Thurer RE, Hutchins GM, Schnitt SJ, Grossmen W, McKay RG. Postmortem and intraoperative balloon valvuloplasty of calcific aortic stenosis in elderly patients: mechanism of successful dilation. JACC $1987 \cdot 9 \cdot 655-660$.

20. Sandor GGS, Olley PM, Trusleer GA, Williams WG, Rowe RD, March JE. Long-term follow-up of patients after valvotomy for congenital valvular aortic stenosis in children. $J$ Thorac Cardiovasc Surg 1980:80:171-176.

21. Jones $M$, Barnhart GR, Morrow AG. Late results after operations for left ventricular outflow tract obstruction. Am J Cardiol 1982:50:569-579.

22. Fisher RD, Mason DT, Morrow AG. Results of operative treatment in congenital aortic stenosis. Pre- and postoperative hemodynamic evaluations. Thorac Cardiovasc Surg 1970:59:218-224.

23. Hossack KF, Neutze LM, Lowe JB, Barratt-Boyes BG. Congenital valvar aortic stenosis: natural history and assessment for operation. Br Heart 1980;43:561-573.

24. Ankeney JL, Tzeng TS, Liebman J. Surgical therapy for congenital aortic valvular stenosis. $J$ Thorac Cardiovasc Surg 1983:85:4I-48.

25. Presbitero P, Somerville J, Revel-Chion R, Ross D. Congenital aortic stenosis, late results. Br Heart J 1982:47:26-34.

26. Conkle DM, Jones M, Morrow AG. Treatment of congenital aortic stenosis. Arch Surg 1973;107:649-651.

27. Jack WD, Kelly DT. Long-term follow-up of valvulotomy for congenital aortic stenosis. Am I Cardiol 1976:38:231-234

28. Wagner HR, Ellison RC, Keane JF, Humphries JO, Nadas AS. Clinical course in aortic stenosis. Circulation 1977;56(suppl 1):147-157.

29. Hsieh KS, Keane JF, Nadas AS, Bernhard WF, Castaneda AR. Long-term follow-up of valvotomy before 1968 for congenital aortic stenosis. Am J Cardiol 1986,58:338-341.

30. McKay RG, Safian RD, Lock JE, Mandeli VS, Thurer RL, Schnitt SJ Grossman W. Balloon dilatation of calcific aortic stenosis in elderly patients. Postmortem, intraoperative, and percutaneous valvuloplasty studies. Circulation 1986:74:119-125.

31. Pelech A, Dyck J, Freedom R, Olley P, Williams WG. Critical aurtic stenosis in the neonate: survival and management (abstr). Circulation 1984,70(supp II): $/ I-132$

32. Lees MH, Hauch AJ, Starkey GWB, Nadas AS, Gross RE. Congenital aortic stenosis: operative indications and surgical results. Br Heart J 1961;24:3I39.

33. Keane JF, Bernhard WF, Nadas AS. Aortic stenosis in infancy. Circulation 1975.52:1138-1145.

34. Trinkle JK, Bernhard WF, Nadas AS. Aortic valvotomy in infants. Lat results. J Thorac Cardiovasc Surg 1978;76:198-206

35. Edmunds LH, Wagner HR. Heymann MA. Aortic valvulotomy in neonates. Circulation 1980,61:421-432.

36. Brown JW, Robinson RJ, Waller BF. Transventricular balloon catheter antic valvotoniy in neonates. Ann Thuruc Surg 1985-39.376-378. 